REVISTA VIRTUAL VIA INVENIENDI ET IUDICANDI

"CAMINO DEL HALLAZGO Y DEL JUICIO"

http://viei.usta.edu.co/ E-MAIL: revistainveniendi@usantotomas.edu.co

\title{
EL PACTO DE ARRAS EN LOS CONTRATOS DE DERECHO PRIVADO
}

\section{Jorge Oviedo Albán}

Fecha de recepción: 28 de febrero de 2010

Fecha de aprobación: 3 de marzo de 2010

Resumen: El pacto de arras, bien sea simples o de retracto, o en sus funciones confirmatoria o confirmatorias penales, se encuentra frecuentemente en contratos de Derecho colombiano, sobre todo cuando se trata de ventas o promesas de venta. No obstante, suelen surgir varios problemas prácticos derivados tal vez del desconocimiento de la figura y sus verdaderos alcances.

El presente escrito tiene por objeto plantear y describir los conceptos básicos necesarios para entender esta figura, al igual que algunas cuestiones de orden práctico que es conveniente considerar para evitar algunas imprecisiones a la hora de incorporarlas a un contrato.

Profesor de Contratos civiles y comerciales en la Facultad de Derecho de la Universidad de La Sabana (Colombia). Director del Área de Derecho Privado y del Grupo de Investigación en Derecho Privado Universidad de La Sabana. Corresponsal en América Latina de "The global sales law project" University of Basel, Suiza. Profesor invitado en la Maestría en Contratación Pública y Privada de la Universidad Santo Tomás y en la Maestría en Derecho en la Universidad Sergio Arboleda. Correo electrónico: jorge.oviedo@unisabana.edu.co. Trabajo producto del Grupo de Investigación en Derecho Privado Universidad de La Sabana. 


\section{Palabras clave:}

Contratos, compraventa, promesa, arras.

\section{Abstract}

Arrha confirmatoria and Arrha poenitentialis are common covenants in Colombian Law contracts, especially when it comes to sales, or sales promises. However, several practical problems often arise from ignorance of the might of the figure and its true scope.

The objective of this paper is describe the basic elements necessary to understand this concept, as well as some practical issues that should be considered to avoid a few inaccuracies when incorporated into a contract.

\section{Key words:}

Contracts, sales of goods, Arrha confirmatória, Arrha poenitentialis. 


\section{SUMARIO}

Introducción. I. Concepto y antecedentes. II. Arras simples o de retracto. 1. Naturaleza jurídica y contenido. 2. Contratos en los que pueden pactarse. 3. Efectos derivados del ejercicio del derecho de retracto. 4. Efectos derivados del no ejercicio del derecho de retracto. 5. Arras simples y cláusula penal. III. Arras confirmatorias. 1. Naturaleza jurídica y contenido. 2. Contratos en los que pueden pactarse. 3. Efecto. IV. Arras confirmatorias penales. V. Conclusiones. Bibliografía.

\section{INTRODUCCIÓN}

En Colombia, es frecuente encontrar incluido en los contratos al pacto de arras, bien sea simples o de retracto o en sus funciones confirmatoria o confirmatorias penales, sobre todo cuando se trata de ventas o promesas de venta. No obstante, suelen surgir varios problemas prácticos derivados tal vez del desconocimiento de la figura y sus verdaderos alcances.

El presente escrito, que se basa en el estudio dogmático de las normas colombianas que regulan las arras además de la consulta de la doctrina y la jurisprudencia de la Corte Suprema de Justicia, tiene por objeto plantear y describir los conceptos básicos necesarios para entender esta figura, que es 
conveniente considerar para evitar algunas imprecisiones a la hora de incorporarlas a un contrato. Valga aclarar que aunque el artículo ha sido elaborado desde la perspectiva del Derecho civil y comercial colombiano, en varios puntos haremos referencia a la regulación que el tema tiene en algunas codificaciones extranjeras, concretamente europeas y latinoamericanas, para lo que hemos escogido algunas de las más representativas, con el fin de lograr un mejor entendimiento de las reglas nacionales desde la perspectiva comparada.

\section{CONCEPTO Y ANTECEDENTES}

Las arras, desde el punto de vista de su regulación en el Derecho Privado colombiano - civil y comercial - no son susceptibles de ser definidas de forma general, puesto que debe verse su clasificación y función de cada uno de los tipos especiales.

El pacto de arras es antiguo y como se verá en las líneas siguientes, pasó por el Derecho medieval hasta llegar a las codificaciones modernas, aunque con una regulación que no es uniforme y que presenta matices diferenciales ${ }^{1}$.

\footnotetext{
${ }^{1}$ En este sentido lo destaca HERnÁndEZ GIL, al afirmar que en las diferentes etapas de su historia, las arras "...se configuran con matices perfectamente diferenciados, incluso puede decirse que su función esencial es netamente contrapuesta". HERNANDEZ GIL, FELIX, Las arras en el derecho de la contratación (en torno al artículo 1.454 del Código Civil), Universidad de Salamanca, Salamanca, 1958, pág. 13.
} 
Como es sabido, el pacto de arras era conocido por el Derecho Romano donde en principio tuvo una función de prueba de la celebración de un contrato y consistieron en una suma de dinero o un bien mueble, como un anillo².

Así entonces, la función primitiva fue netamente probatoria, puesto que con ellas se pretendía demostrar que se había celebrado un contrato ${ }^{3}$. Así aparecen en las Institutas de GAYO:

"La compraventa se contrae cuando se ha convenido precio, a pesar de que no se haya dado todavía una cantidad de dinero o arras, pues lo que se da como arras es sólo una señal de que se ha contraído la compraventa"4.

2 Alessandri Rodríguez, ARtURo, De la compraventa $i$ de la promesa de venta, t. 1, Imprenta litográfica Barcelona, Santiago, 1918, pág. 113. Igualmente ZIMMERMANN indica que usualmente consistían en un anillo o una suma de dinero. ZIMMERMANN, REINHARD, The law of obligations. Roman foundations of the civilian tradition, Oxford, New York, 1996, pág. 230. Aunque GUZMÁn BRITO les atribuye un origen helenístico. “... por influencia de los derechos helenísticos, ingresó en la costumbre romana la figura de las "arras" (arrae, arrhae). La palabra arra (arrha) es forma popular de arrabo, transliteración del griego arrabón, que lo es a su vez de una expresión semítica que significa "garantía". GuZmán Brito, Alejandro, Derecho Privado Romano, Tomo II, Editorial Jurídica de Chile, Santiago, 2001, pág. 127. En el mismo sentido CoMPAGnuCCI DE CASO, RubÉN H., Contrato de compraventa, Hammurabi, Buenos Aires, 2007, pág. 344. Igualmente: D’Ors, Alvaro, Derecho Privado Romano, 10 a edición, Eunsa, Pamplona, 2004, pág. 554. ZiMMERMANN, ob. cit, págs. 230 a 234. Véase también sobre el origen de las arras: RODRÍGUEZ FONNEGRA, JAIME, Del contrato de compraventa y materias aledañas, Ediciones Lerner, Bogotá, 1960, págs. 1052 a 1056. Sobre las arras en el Derecho Romano: CARVAJAl R, PAtricio-IGnacio, "Las Arras en el Derecho Justinianeo", en Revista chilena de Derecho, vol.33, no.3, (2006), págs. 529 a 560.

3 Alterini, Atilio Anibal, Contratos. Civiles - Comerciales - De consumo. Teoría General, Abeledo Perrot, Buenos Aires, 1998, pág. 400. HeRnándEz GIL, ob. cit, pág. 14. 
Este efecto probatorio que tenían las arras en el período clásico perduraría hasta la época justinianea. En efecto, se atribuye a JUSTINIANO el haber dado a las arras una función de retracto, de forma que bien fuere el vendedor o el comprador podían retirarse del contrato con la consecuencia para el comprador de perder las arras y para el vendedor, restituirlas dobladas ${ }^{5}$.

Con este doble objeto (medio de prueba y de retractación) el pacto de arras seria acogido por la legislación española en la ley $7^{a}$, título $\vee$ de la partida $\vee$ y por esa vía llegarían al Código de BELLO ${ }^{6}$. Efectivamente, así dispone el texto en mención:

"Señal dan los omes unos a otros en las ventas e acaesce después que se arrepiente alguno. E por ende dezimos que si el comprador se arrepiente después que da la señal que la debe perder; mas si el vendedor se arrepiente después debe tornar la señal doblada al comprador e non valdrá después la vendida. Pero

4 Gayo 3. 139. Instituciones jurídicas de GAYO, texto y traducción Francisco Samper, Editorial Jurídica de Chile, Santiago, 2000, pág. 273.

${ }^{5}$ AlESSANDRI, ob. cit., págs. 113 a 114. VÉLEZ, FERnANDO, Estudio sobre el Derecho Civil Colombiano, tomo séptimo, Imprenta oficial, Medellín, 1909, pág. 180. ZIMMERMANN, ob. cit, pág. 233. HERNÁNDEZ GIL, afirma que las arras poenitentialis, acogidas en el período postclásico provenían del Derecho griego donde cumplían una doble función: medio de garantía o un negocio preparatorio de una compraventa futura con la facultad de desistir de la promesa con el efecto para quien las dio de perderlas o restituirlas dobladas por el receptor. HERNÁNDEZ GIL, ob. cit., pág. 16.

${ }^{6}$ AlessandRI, ob. cit., pág. 114. Véase igualmente SAMPER, FRANCISCO, Derecho romano, $2^{\mathrm{a}}$ edición, Pontificia Universidad Católica de Chile, Santiago, 2007, pág. 373. 
si cuando el comprador dio la señal dixo asi: que la dava por señal e por parte del precio, o por otorgamiento non se puede arrepentir nongono de ellos ni desfacer la vendida que non vala"

DOMAT, sin distinguir si el contrato se incorporan las arras es preliminar 0 definitivo, señaló que las arras consisten en algo que se da en prenda de parte del comprador al vendedor, asignándoles las siguientes funciones: bien sea para garantizar que se entiende perfeccionado el contrato, como parte del precio o estimación de los daños en caso de incumplimiento, dependiendo de lo que las partes quisieren, aunque señalando que si no hubiere pacto expreso entre ellas acerca de la función que tendrían las arras, se debiera entender que en caso de incumplimiento el comprador las pierde y el vendedor las restituye dobladas ${ }^{8}$. En la obra de POTHIER también aparecen con una doble función, aunque el autor consideró que las arras debían clasificarse en las que se dan antes de concluido el

\footnotetext{
7 VII PARTIDAS DEL SABIO REY DON ALFONSO EL IX, con las variantes de más interes y con La Glosa del Lic. Gregorio López, Barcelona, Imprenta de Antonio Bergnes, 1843-1844, pág. 69. Sobre la evolución de las arras en el derecho histórico español véase HERNÁNDEZ GIL, ob. cit., págs. 23 a 27.

${ }^{8}$ DomAt, J., Las leyes civiles en su orden natural, edición española de Felio Vilarrublas y José Sardá, 2a edición, Barcelona, 1844, pág. 160.
} 
contrato y arras que se dan después de concluido el contrato. De esta forma, las primeras tendrían el carácter penitencial y las segundas confirmatorio ${ }^{9}$.

En varios de los códigos modernos de la tradición romano germánica, aparecen consagradas, aunque con efectos no plenamente coincidentes ${ }^{10}$. A varios de ellos haremos referencia a manera de concordancias en las páginas siguientes.

En el Derecho colombiano, la regulación sobre arras se encuentra presente en los artículos 1859 a 1861 y 1979 del Código Civil colombiano y en el artículo 866 del Código de Comercio. Los artículos del Código Civil están contenidos en el capítulo de compraventa y arrendamiento, lo que en principio no impide que en otros contratos también puedan pactarse arras, tal como se verá. Por su parte, la norma mercantil las regula en la parte general del libro cuarto sobre obligaciones y contratos, admitiéndolas para todo tipo de contrato.

\section{ARRAS SIMPLES O DE RETRACTO}

\footnotetext{
9 PothIER, JosePh, Tratado del contrato de compra y venta, traducido al español y con notas del derecho patrio por una sociedad de amigos colaboradores, Imprenta y Litografía de J. Roger, Barcelona, 1841, págs. 250 a 255.

${ }^{10}$ HeRnÁNDEZ GIL, ob. cit., pág. 19.
} 
Tanto el artículo 1859 del Código Civil como el 866 del Código de Comercio, describen a las arras simples (o penitenciales como las llaman algunos $)^{11}$, señalando que consisten en algo que se da en "prenda" de la celebración de un contrato con el fin de garantizar el cumplimiento efectivo de las obligaciones de las partes, de tal forma que cada uno de los contratantes se puede retractar, el que las dio perdiéndolas y el que las recibió, restituyéndolas dobladas $^{12}$.

No existe en la legislación nacional norma alguna que sugiera que las arras las deba dar tan sólo una de las partes. Ante ello, es evidente que las puede dar cualquiera: como bien puede ser el promitente vendedor o promitente comprador,

${ }^{11}$ GÓMEZ ESTRADA, CÉSAR, De los principales contratos civiles, 4 a edición, Temis, Bogotá, 2008, pág. 27. Dice GUZMÁn BRITO: "En el derecho común se llamó "arrae paenitentiales" a aquellas que aseguran la conclusión del contrato (art. $1803 \mathrm{CC}$ ), y "arrae poenalis" a las que garantizan su cumplimiento (art. $1805 \mathrm{CC}$ ). CARVAJAL, señala que éstas "...toman la forma aproximada de la cláusula penal - en cuanto cumplen una función indemnizatoria $\mathrm{o}$, lo mismo, satisfactoria-, a favor de la parte que ha perseverado en el contrato". CARVAJAL, ob. cit., pág. 531. GUZMÁn BRITO, ob. cit., pág. 128.

${ }^{12}$ El artículo 1859 del Código Civil establece: "Si se vende con arras, esto es, dando una cosa en prenda de la celebración o ejecución del contrato, se entiende que cada uno de los contratantes podrá retractarse; el que ha dado las arras, perdiéndolas, y el que las ha recibido, restituyéndolas dobladas".

Por su parte, el artículo 866 del Código de Comercio: "Cuando los contratos se celebren con arras, esto es, dando una cosa en prenda de su celebración o de su ejecución, se entenderá que cada uno de los contratantes podrá retractarse, perdiendo las arras el que las haya dado, o restituyéndolas dobladas el que las haya recibido.

Celebrado el contrato prometido o ejecutada la prestación objeto del mismo, no será posible la retractación y las arras deberán imputarse a la prestación debida o restituirse, si fuere el caso". 
si se pactaren en la promesa o la parte vendedora o compradora si se pactaren en la venta o en definitiva las partes de cualquier contrato donde se quieran incluir. Ello se deriva de una simple lectura del artículo 1859 del Código Civil ${ }^{13}$.

\section{NATURALEZA JURÍDICA Y CONTENIDO}

A efectos de precisar la naturaleza jurídica de las arras simples, debe hacerse una aclaración de tipo terminológico, toda vez que el artículo 1859 del Código Civil establece que consisten en algo que se da en "prenda". Consideramos que el vocablo "prenda" está aquí mal utilizado ${ }^{14}$.

En el contexto del Código Civil, las "garantías" se refieren a contratos accesorios, cuya función es asegurar el cumplimiento de obligaciones derivadas de contratos principales, tal como se señala en el artículo 1499 del mismo. Las obligaciones derivadas de tales garantías, que pueden ser reales o personales, están sometidas a una condición suspensiva negativa, toda vez que no podrán ser exigibles ni ejecutadas hasta tanto no acaezca la condición negativa de la cual penden, como es el incumplimiento del deudor de la obligación principal.

\footnotetext{
13 "Como el artículo (...) no habla ni de vendedor ni de comprador, sino que de los contratantes, es indudable que se refiere a ambos. De modo que tanto uno como el otro pueden dar las arras, con lo cual nuestro Código innovó sobre el Derecho romano en que, de ordinario, era el comprador quien las daba únicamente”. ALESSANDRI, ob. cit., pág. 117.

${ }^{14}$ De todas formas, cabe señalar que en las obras antiguas, como en DOMAT, se utilizaba el vocablo prenda, para calificar a las arras. Cfr. DOMAT, ob. cit., pág. 160.
} 
Así, el contrato de prenda, consagrado en el artículo 2409 del Código Civil, consiste en medio de garantía por el que se entrega una cosa mueble a un acreedor para la seguridad de su crédito ante un eventual incumplimiento de las obligaciones del deudor, de forma que genera un derecho real, con los atributos de persecución y preferencia ${ }^{15}$.

De esta forma, si las arras verdaderamente fueren una "garantía" tal vez de carácter real como la prenda o la hipoteca, se estaría vinculando un bien al hecho del incumplimiento de una de las partes, que debería ser quien las entrega. Pero sucede todo lo contrario, puesto que las arras no solamente las puede dar cualquiera de los contratantes, sino que además, su verdadero efecto - como insistiremos- será el de permitir a cualquiera de ellos, el que las dio o las recibió, el derecho lícito de retracto sin que tal hecho signifique incumplimiento del contrato y por ende no da lugar a las acciones derivadas de tal situación como son la ejecución forzosa o la resolución del contrato con indemnización de perjuicios ${ }^{16}$.

${ }^{15}$ ALESSANDRI, ob. cit., pág. 117.

${ }^{16}$ Pérez Vives, Álvaro, Teoría general de las obligaciones, volumen 1, parte primera, $2^{\mathrm{a}}$ edición, Universidad Nacional de Colombia, Bogotá, 1957, pág. 97. En el Derecho español lo destaca igualmente de esta forma Díez PICAZO: "La función de las llamadas arras penitenciales o arras de desistimiento no es de garantía. Sólo puede encontrarse un atisbo de esta función en la medida en que la onerosidad que significa la pérdida de lo entregado para quien hizo la entrega o de la restitución del duplo para quien las recibió, actuará entre las partes como un medio de presión hacia el cumplimiento. Sin embargo, el núcleo central de esta figura es la facultad liberatoria o de desistimiento que constituye una facultad solutoria o facultad alternativa". DíEz PICAZO, LuIS, Fundamentos del Derecho Civil patrimonial, II, las relaciones obligatorias, $6^{\mathrm{a}}$ edición, Thomson Civitas, Cizur Menor, 2008, pág. 472. Adicionalmente MESSINEO quien insiste que la seña no debe confundirse 
Así lo ha considerado la Corte Suprema de Justicia colombiana al señalar que: "Efecto propio de las arras penitenciales es, pues, el de autorizar a cada una de las partes el desistimiento del contrato, dentro del plazo estipulado o, a falta de éste, dentro de los dos meses siguientes a la convención. La facultad de retractación, en tal caso, no es para detener la ejecución del contrato sino para deshacerlo retroactivamente por voluntad unilateral; el contratante que lo ejerce no se sustrae a las obligaciones por él contraídas, sino que simplemente usa un derecho que se le ha concedido, sometiéndose al pago estipulado para la retractación, que viene a ser el precio del derecho de su arrepentimiento.

« Lo cual significa que los otorgantes, relativamente al contrato, se reservan la facultad de deshacerlo unilateralmente sin necesidad de acudir al Órgano Jurisdiccional del Estado, pues que en tal supuesto el convenio queda deshecho extraprocesalmente y como obvia consecuencia del ejercicio de la facultad legítima de retracto por parte de uno de los contratantes. Por lo mismo, la no ejecución del pacto por el contratante que se retracta no puede ser calificada de incumplimiento y por ende resulta también improcedente la pretensión de

con una caución que es la que funciona realmente como una garantía. MESSINEO, Francesco, Doctrina general del contrato, R.O. Fontanarrosa, S. Sentis Melendo, M. Volterra, (trads.), t. 1, Ediciones Jurídicas Europa América, Buenos Aires, 1986, pág. 224. 
cumplimiento que, alternativamente con la resolutoria, consagra el artículo 1546 del Código Civil colombiano"17.

Cabe agregar que la Corte Suprema de Justicia ha reconocido a las arras un carácter accesorio, tal vez no por afirmar que constituyan una garantía, sino porque consisten en una estipulación “...vinculada como tal a la validez del contrato principal a que accede" ${ }^{18}$. Igualmente, ha insistido la Corte, en que no toda entrega de dinero al momento de celebración del contrato debe entenderse como pacto de arras si no existe expresa conciencia y acuerdo entre los contratantes sobre ello ${ }^{19}$.

${ }^{17}$ Corte Suprema de Justicia, Sala de Casación Civil, 10 de mayo de 1977, M.P. Humberto Murcia Ballen, G.J., t. CLV, núm. 2396, 1977, pág. 106.

${ }^{18}$ Corte Suprema de Justicia, Sala de Casación Civil, 30 de julio de 1941, M.P. Hernán Salamanca, G.J., t. LII, n 1977, 1941, pág. 18.

${ }^{19}$ Corte Suprema de Justicia, Sala de Casación Civil, 30 de julio de 1941, cit. En esta ocasión señaló la Corte: "Las cosas que las partes se dan en el desarrollo de un negocio de venta no tienen por sí mismas, por el hecho de darse, el significado y valor jurídico que corresponde a las arras, si expresamente no se ha convenido en darles el carácter de prenda, esto es, que se han entregado en el concepto o calidad convencional de arras. Sólo en estas condiciones quedan las cosas afectas a las consecuencias que para el caso determina la ley a través de la estipulación especial de este pacto". En igual sentido lo estimó en sentencia de 1953: "Según los doctrinantes y lo que significan las arras, su estipulación es siempre expresa; pues, de no, la entrega de dinero debe considerarse como un anticipo del precio en los contratos de compraventa o en aquellos en que se promete celebrar no de tal naturaleza". Corte Suprema de Justicia, Sala de Casación Civil, 10 de julio de 1953, M.P. Pablo Emilio Manotas, G.J., t. LXXV, n 2129, 1953, pág. 548. 
Igualmente, debemos destacar que la Corte Suprema de Justicia ha señalado que el pacto de arras es de naturaleza real, al entender que se requiere su entrega para que produzca los efectos respectivos. Según esta postura, si se verifica la redacción del artículo 1859 del Código Civil, se tiene que éste establece la naturaleza real de las arras, al señalar que las arras simples consisten en la entrega de una $\operatorname{cosa}^{20}$.

No obstante y siguiendo en ello a DE LA PUENTE y LAVALLE, consideramos que cabe perfectamente distinguir entre el pacto de arras que salvo que las partes dispongan otra cosa es consensual, entendiéndose incorporado en el contrato que lo contenga desde que las partes lo acuerden y la entrega de las arras propiamente tal, que es un efecto derivado de aquél ${ }^{21}$.

Adicionalmente, tiende a creerse que las arras solo pueden consistir en dinero, lo cual no es exacto. Las normas en comento no requieren que las arras

${ }^{20}$ Corte Suprema de Justicia, Sala de Casación Civil, 30 de julio de 1941, cit.

${ }^{21}$ Tal como lo señala De LA Puente y LAVALLE al comentar el artículo 1477 del Código Civil peruano que consagra las arras confirmatorias, la mayoría de la doctrina en Derecho comparado entiende que es un pacto de naturaleza real. No obstante, el mismo autor disiente de esta posición al considerar que hay que distinguir el pacto arral y la entrega de las arras confirmatorias afirmando que el primero, de carácter consensual y que antecede al segundo, es el que genera el efecto probatorio. De la Puente y LaVALle, Manuel, El contrato en general, comentarios a la sección primera del libro VII del Código Civil, Biblioteca para Leer el Código Civil, vol. XV, segunda parte, tomo VI, Pontificia Universidad Católica del Perú, Lima, 1999, págs. 176 a 179. POTHIER las consideraba como un pacto real. PотHIER, ob. cit., pág. 250. Entre los autores latinoamericanos contemporáneos en sentido de considerarlas un pacto real, véase: MOSSET ITURRASPE, JoRge, Contratos, Rubinzal Culzoni editores, Santa Fe, 2003, pág. 454. 
consistan en dinero, sino que se refieren a "algo" que se da como garantía de la celebración o ejecución del contrato. Así entonces, nada obsta para que se dé a título de arras cualquier otro tipo de bien, incluso de la misma naturaleza de la cosa objeto del contrato.

\section{CONTRATOS EN LOS QUE PUEDEN PACTARSE}

Las arras simples como garantía de celebración del contrato, deben pactarse necesariamente en un momento anterior a la celebración del contrato. Esto significa que para que cumplan esta función, las arras deberán pactarse en un momento anterior al contrato definitivo, como es lo que sucede al incluirse en el contrato de promesa. Lo usual en el Derecho colombiano, es que las partes pacten en el contrato de promesa arras simples como garantía de celebración del contrato prometido. Por su lado, las arras simples como garantía de ejecución se incluirán en el contrato definitivo ${ }^{22}$.

${ }^{22}$ El Código Civil francés regula las arras en el artículo 1590, señalando que en el contrato
de promesa de venta y establece que si se dieren arras, cada uno de los contratantes puede
desligarse de ellas perdiéndolas el que las entregó y restituyéndolas dobladas el que las
recibió. De tiempo atrás la doctrina francesa ha señalado que a pesar de estar reguladas en
las promesas, “...como el Código trata de las promesas sinalagmáticas, que son ventas, el
texto se aplica a todas las veces que hay compromiso recíproco de vender y comprar”.
RIPERT, GEORGES; BouLANGER, JEAN, Tratado de Derecho Civil según el tratado de
Planiol, Contratos Civiles, traducción de Delia García Daireaux, La Ley, Buenos Aires,
1965, pág. 63. Igualmente en este sentido y citando autores antiguos: PLANIOL, MARCELO;
RIPERT, JORGE, Tratado práctico de Derecho Civil francés, tomo X, Los contratos civiles,
traducción española de Mario Díaz Cruz con la colaboración de Eduardo Le Riverend
Brusone, Cultural S.A., Habana, 1940, págs. 223, 224. En el Código Civil peruano, sin 
No obstante, cabe recordar que en un fallo de 1953 la Corte Suprema de Justicia consideró que en el contrato de promesa no cabía pactar arras simples. Dijo la Corte en esta ocasión:

"No puede discutirse que promesa de contrato y arras, en derecho colombiano son dos negocios incompatibles por regla general, puesto que las arras en nuestro derecho tienen un significado general o preponderante de medio para desdecirse, o retractarse, de un contrato, o sea, que son penitenciales, en principio; tesis ésta indiscutible, sobre todo en presencia del segundo inciso del art. 1681, que llega hasta consagrar una presunción de derecho, en el pacto de arras, como significativa de la facultad de retractarse que se reservan los contratantes" ${ }^{\prime 23}$.

distinguir la función de garantizar la celebración de un contrato o su cumplimiento, el artículo 1480 establece que "La entrega de las arras de retractación sólo es válida en los contratos preparatorios y concede a las partes el derecho de retractarse de ellos". El Código Civil italiano de 1942 se refiere a la "seña penitencial" en el artículo 1386 ubicado en las normas generales: "Si en el contrato se hubiese estipulado el derecho de rescisión a favor de una o de ambas partes, la seña tendrá únicamente la función de retribución de la rescisión. En este caso, el que rescindiere perderá la seña dada o deberá restituir el doble de la recibida". Igualmente, en el Código Civil argentino, en el artículo 1202, también ubicado en las normas generales de obligaciones, que dispone: "Si se hubiere dado una señal para asegurar el contrato o su cumplimiento, quien la dio puede arrepentirse del contrato, o puede dejar de cumplirlo perdiendo la señal. Puede también arrepentirse el que la recibió; y en tal caso debe devolver la señal con otro tanto de su valor. Si el contrato se cumpliere, la señal debe devolverse en el estado en que se encuentre. Si ella fuere de la misma especie que lo que por el contrato debía darse, la señal se tendrá como parte de la prestación; pero no si ella fuere de diferente especie, o si la obligación fuese de hacer o de no hacer".

${ }^{23}$ Corte Suprema de Justicia, Sala de Casación Civil, 6 de octubre de 1953, M.P. Pablo Emilio Manotas, G.J., t. LXXVI, n 2133, 1953, pág. 506. 
En este mismo fallo, la Corte Suprema determinó que las arras cumplirían una función de estimación de perjuicios en caso de incumplimiento de la promesa:

“...en caso de probarse incumplimiento del contrato de promesa, y cuando se ha elegido acción resolutoria, no habría lugar para una condena a daños y perjuicios determinables en el pleito, con la intervención de peritos, sino que debería atenerse la solución del problema al pago de las arras penales, aplicando por analogía el principio consignado en el art. 1600, cuando la parte interesada ha pedido la resolución del contrato con la consiguiente indemnización de perjuicios, la cual como es obvio, está fijada en el pacto de arras" ${ }^{24}$.

Esta tesis fue superada por sentencia de 1967, en la que la Corte Suprema consideró:

"Nuestro Código Civil habla de las arras únicamente en los contratos de compraventa y de arrendamiento (artículos 1859, 1860, 1861, 1932 y 1979). Lo cual no quita, como está visto atrás, el que puedan estipularse en cualquiera de sus especies, en otros contratos, en uso de la libertad de contratación, por cuanto ni la ley lo impide, ni repugna ello a la índole de las arras según ha sido explicado. Su regulación por el Código Civil, en relación con la compraventa, nada tiene de excepcional y restrictivo, pues no se ofrece con tal carácter y, así, las normas al respecto, a virtud de lo dispuesto en el artículo $8^{\circ}$ de la Ley 153 de 1887, son

${ }^{24}$ Corte Suprema de Justicia, Sala de Casación Civil, 6 de octubre de 1953, cit. 
susceptibles de aplicación por analogía al pacto de arras en relación con otros contratos, en tanto el derecho no lo prohíba. Entonces, la estipulación de arras de retractación es de recibo, tanto en la promesa bilateral de compraventa como en la promesa unilateral de venta o de compra" ${ }^{25}$.

Cabe agregar, tal como ya lo ha considerado la Corte Suprema de Justicia, que a pesar de estar las arras reguladas en el Código Civil en las reglas de compraventa (artículos 1859 a 1861) y para el arrendamiento (artículos 1932 y 1979), nada obsta para que también puedan pactarse en otros contratos ${ }^{26}$. En efecto:

"Nuestro Código Civil habla de las arras únicamente en los contratos de compraventa y de arrendamiento (artículos 1859, 1860, 1861, 1932 y 1979). Lo cual no quita, como está visto atrás, el que puedan estipularse en cualquiera de sus especies, en otros contratos, en uso de la libertad de contratación, por cuanto ni la ley lo impide, ni repugna ello a la índole de las arras, según ha sido explicado. Su regulación por el Código Civil, en relación con la compraventa, nada tiene de excepcional y restrictivo, pues no se ofrece con tal carácter y, así, las normas al

${ }^{25}$ Corte Suprema de Justicia, Sala de Casación Civil, 21 de febrero de 1967, M.P. Gustavo Fajardo Pinzón, G.J., t. CXIX, núms. 2285 y 2286, 1967, pág. 47. En igual sentido puede verse: Corte Suprema de Justicia, Sala de Casación Civil, 11 de diciembre de 1978, M.P. Alberto Ospina Botero, G.J., t. CLVIII, n 2399, 1978, pág. 311. Corte Suprema de Justicia, Sala de Casación Civil y Agraria, 7 de septiembre de 1999, M.P., Manuel Ardila Velásquez, exp. 5217.

${ }^{26}$ BONIVENTO JiMÉNEZ, JAVIER, El contrato de promesa. La promesa de compraventa de bienes inmuebles, Ediciones Librería del Profesional, Bogotá, 1996, pág. 343. 
respecto, a virtud de lo dispuesto en el artículo $8^{\circ}$ de la Ley 153 de 1887 , son susceptibles de aplicación por analogía al pacto de arras en relación con otros contratos, en tanto el derecho no lo prohíba. Entonces, la estipulación de las arras de retratación es de recibo, tanto en la promesa bilateral de compraventa como en la promesa unilateral de venta o de compra"27.

A diferencia del Civil (aunque el efecto es el mismo), en materia comercial el artículo 866 del Código de Comercio regula la figura de las arras simples en la parte general, aplicables por ende a todo acuerdo contractual (aunque en lo civil también cabría, por aplicación analógica). En dicha norma se consagra igualmente la figura del retracto como efecto de las arras.

\section{EFECTOS DERIVADOS DEL EJERCICIO DEL DERECHO DE RETRACTO}

Las arras simples generan la posibilidad de retractarse lícitamente bien sea de la celebración o de la ejecución del contrato, dependiendo de la función asignada, por lo que el contrato en el que se incluyan queda sometido a una condición resolutoria, toda vez que el mismo se extinguirá si acaece el hecho futuro e incierto que consiste en que cualquiera de las dos partes se retracte del

${ }^{27}$ Corte Suprema de Justicia, Sala de Casación Civil, 21 de febrero de 1967, cit. Cabe agregar que además de las arras simples, también cabe pactar en todo tipo de contratos las confirmatorias y las confirmatorias penales de las que se hablará en las páginas siguientes. 
contrato $^{28}$. Ahora, si se pactaren en un contrato de promesa, para garantizar la celebración del contrato prometido, el nacimiento del prometido si queda sometido a una condición suspensiva negativa, que consiste en que los contratantes no ejerzan el derecho de retracto ${ }^{29}$.

Es frecuente observar que se tiende siempre a exigir el pacto de arras tanto en los contratos de promesa como en los de compraventa, teniendo la idea de que con ellas están garantizando el cumplimiento de lo acordado. Si se medita sobre el real efecto de las arras simples, debemos concluir que las arras pueden resultar peligrosas, toda vez que al incluirlas, lo que se estará permitiendo es que cualquiera de las dos partes, tanto el que las da como el que las recibe, se pueda retractar de forma lícita. Debemos insistir que en realidad no se trata de una

${ }^{28}$ A diferencia de esta afirmación, entre los clásicos franceses debe tenerse en cuenta la opinión de PLANIOL y RIPERT, quienes consideraron que el contrato queda sometido a una condición suspensiva, “...la fijación de una fecha límite para efectuar ese desistimiento podrá interpretarse como una voluntad de establecer una condición suspensiva; la venta no será definitiva más que si en tal o cual fecha ninguna de las dos partes ha desistido de ella". Planiol; RiPert, ob. cit., pág. 225. Igualmente Colin, Ambrosio; CAPITANT, Henri, Curso elemental de Derecho Civil, Demófilo de Buen (Trad.), t. 4, $3^{\text {a }}$ edición, Instituto editorial Reus, Madrid, 1955, pág. 38. En Chile, AlESSANDRI consideró en su momento que las arras consisten en una condición suspensiva negativa a la que se somete el contrato. ALESSANDRI, ob. cit., pág. 118. En Colombia, también GonZÁLEZ ZABALA considera este tipo de arras someten el contrato a una condición resolutoria. GONZÁlEZ ZABALA, MARÍA ClARA, "De las funciones de las arras en el derecho privado colombiano y en el derecho comparado" en Estudios de Derecho Privado, tomo 1, liber amicorum en homenaje a César Gómez Estrada, Universidad del Rosario, Bogotá, 2009, pág. 374

${ }^{29}$ En este sentido: Bonivento JimÉnEZ, ob. cit., pág. 344. Igualmente BAENA UPEGUi, MARIO, De las obligaciones en Derecho Civil y Comercial, $3^{\mathrm{a}}$ edición, Legis, Bogotá, 2000, pág. 198. 
garantía de celebración o de ejecución, sino que consisten en el precio que se paga por poderse retirar libremente del contrato, sin que ello signifique incumplimiento, tal como indicamos anteriormente.

Por esto, es que recomendamos siempre aclarar a los contratantes, en el sentido de lo que podría en realidad llegar a suceder si se incluyeren arras. Si las partes verdaderamente quisieran optar por el retracto, deben incluirse, pero si no, no deben pactarse.

El plazo para ejercer el derecho de retracto, como lo dispone el artículo 1860 del Código Civil, es el que las partes hayan fijado y de forma supletiva, de dos meses siguientes al contrato que las haya incluido. Igualmente establece la norma que no podrá ejercitarse el derecho de retracto, si no obstante estar todavía las partes en tiempo para hacerlo pudiere deducirse que renunciaron de forma tácita a ello, al otorgar escritura pública de venta o principiada la entrega de la $\operatorname{cosa}^{30}$. Un ejemplo simple puede ilustrar sobre el particular: pensemos en un contrato de promesa de venta celebrado el día 20 de agosto de determinado año, en el que las partes prometen celebrar un contrato de venta el día 20 de octubre del mismo año. Supongamos también que las partes pactaron arras simples como

30 VÉLEZ, ob. cit., pág. 182. De todas formas, no parece que la renuncia tácita solo quepa en esos dos eventos, sino cuando haya un "principio de ejecución" de cualquiera de las obligaciones derivadas del contrato. Alterini, Atilio ANIBAL; AMEAL OsCAR José; LóPEZ CABAna, Roberto M., Derecho de obligaciones civiles y comerciales, $3^{\text {a }}$ edición, Lexis Nexis Abeledo Perrot, Buenos Aires, 2006, págs. 128 y 265. 
garantía de celebración del contrato prometido, pero no fijaron el plazo para el ejercicio del derecho de retracto derivado de las arras. Si esto es así, las partes tendrían desde el día de celebración de la promesa, hasta el día de celebración del prometido para retractarse. Sin embargo, pensemos que las partes se encuentran en la notaría en la que debían celebrar el contrato prometido el día 5 de octubre del mismo año y aprovechando la situación celebran el contrato prometido. Por ello, lo que deduce el legislador, es que las partes renuncian de forma tácita al derecho de retracto, al celebrar el contrato prometido en una fecha anterior a la que originalmente habían acordado.

Ahora, si las partes ejercen el derecho de retracto derivado de las arras, el efecto que se produce es el que está señalado en el artículo 1859 del Código Civil, consistente en que si se retracta el que las dio, las pierde y si se retracta el que las recibió las restituye dobladas. En este caso, si se hubieren dado arras en dinero, se devolverá este mas otro tanto, o si se hubiere dado un bien de distinta naturaleza, deberá devolverse el mismo, mas una suma de dinero que lo represente, para que de esta forma pueda entenderse que se devolvió el "doble"31.

A diferencia de la norma civil, la comercial no indica plazo dentro del cual pueda ejercerse el derecho de retracto. La norma solamente establece como

31 ALESSANDRI, señala que podrá además darse el mismo bien original más uno de igual naturaleza o valor. ALESSANDRI, ob. cit., pág. 120. Cfr. C.C. peruano, art. 1481 donde se reconoce el mismo efecto patrimonial. 
causales de caducidad de tal derecho, la celebración del contrato prometido o la ejecución de la prestación objeto del mismo. Ante ello cabe preguntarse si por no fijar el Código de Comercio un término para que caduque el derecho de retracto supletivo del que podrían pactar las partes, deba entenderse que dicho plazo no existe. En la doctrina, el Profesor Suescún Melo piensa que esta disposición, “...no fija un plazo para ejercer la facultad de desistimiento, de manera que puede ejercerse hasta la celebración del contrato prometido o hasta la ejecución misma de la prestación objeto del contrato"32.

A diferencia de esta opinión, consideramos que el plazo supletivo para que caduque el derecho de retracto es el mismo civil de dos meses por la siguiente razón: debe recordarse que el artículo 822 del Código de Comercio hace un llamado directo a la legislación civil en la regulación de actos y contratos en punto de la formación, efectos, interpretación, modo de extinguirse anularse o rescindirse, a menos que la ley establezca otra cosa. Ante el silencio de la norma mercantil en punto del plazo que los contratantes tienen para retractarse, no podemos pensar que el Código de Comercio reguló el tema de manera diferente, razón por la cual bien cabe acudir a la norma civil para llenar el aparente vacío.

32 Suescún Melo, Jorge, Derecho Privado. Estudios de Derecho Civil y Comercial contemporáneo, t. I, 2a edición, Universidad de los Andes, Legis, Bogotá, 2003, pág. 43. De la misma forma ARrubla PAUCAR, JAIMe Alberto, Contratos mercantiles, tomo 1, teoría general del negocio mercantil, 12a edición, Dike, Medellín, 2007, pág. 176 y NARVÁEZ GARCÍA, JosÉ IGNACIO, Derecho mercantil colombiano. Obligaciones y contratos mercantiles, $2^{\text {a }}$ edición, Legis, Bogotá, 2002, pág. 148. 
Además, la norma en comento no está en realidad regulando de manera diferente el tema, puesto que lo único que hace es reiterar al igual que la legislación civil, que el derecho de retracto caduca si se celebra el contrato prometido o se ejecuta la prestación objeto del mismo. Cosa diferente sucedería si la norma estableciera que el derecho de retracto puede ejercerse desde el momento del pacto hasta la celebración del contrato prometido, puesto que ahí si se entendería que fijó un plazo diferente al civil.

\section{EFECTOS DERIVAdOS DEL NO EJERCICIO DEL DERECHO DE RETRACTO}

¿Qué sucedería si las partes no obstante poder hacerlo, no ejercen el derecho de retracto?. Al no ejercerlo, bien porque renuncian expresa o tácitamente al derecho de retracto o porque caduca, las partes deberán cumplir lo pactado, ya sea celebrando el contrato prometido o ejecutando las obligaciones del contrato definitivo, según sea el caso. ¿Qué pasará con las arras en tales eventos?.

La parte que las haya recibido tiene la obligación de devolverlas, pues no hay causa que la legitime a quedarse con ellas ${ }^{33}$. Se tiende a creer que si no se ejerce el derecho de retracto, las arras se deben imputar al precio. Esto no ocurre en todos los casos pasamos a demostrarlo.

33 AlESSANDRI, ob. cit., pág. 120. 
En algunos eventos habrá lugar a imputarlas a la prestación debida, tal como lo establece el inciso 2 del artículo 866 del Código de Comercio: "Celebrado el contrato prometido o ejecutada la prestación objeto del mismo, no será posible la retractación y las arras deberán imputarse a la prestación debida o restituirse, si fuere el caso"34. La cuestión amerita el análisis de varias posibles situaciones, suponiendo que se pactan en un contrato de venta:

La primera consiste en que el vendedor da dinero a título de arras.

Aunque el caso puede resultar meramente hipotético pues en la práctica no suele pactarse de esa forma, cabe de todas formas para efectos del análisis pensar en que si las arras consisten en dinero y las da el vendedor, el comprador tiene la obligación de devolverlas, siendo entonces deudor del precio derivado del contrato y de las arras que recibió en dinero.

La segunda situación es que las arras consistan en dinero y las dé el comprador.

\footnotetext{
${ }^{34}$ En el Código Civil peruano se establece en términos similares la regla que determina el destino de las arras a la celebración del contrato definitivo. Así se establece en el artículo 1483: "Si se celebra el contrato definitivo, quien recibe las arras las devolverá de inmediato o las imputará sobre su crédito, según la naturaleza de la prestación”. Igualmente, el artículo 1202 del Código Civil argentino.
} 
Es en este caso que las arras se deben imputar al precio, puesto que al tener que devolverlas el vendedor y el comprador tener que pagar el precio de la venta, operará la figura de la compensación consagrada en el artículo 1714 del Código Civil, que establece: "Cuando dos personas son deudoras una de otra, se opera entre ellas una compensación que extingue ambas deudas...". Para que ello ocurra, deben darse los requisitos del artículo 1715 del Código Civil, a saber: que ambas sean en dinero o de cosas fungibles o indeterminadas de igual género y calidad; que ambas deudas sean líquidas y que ambas sean actualmente exigibles.

La tercera posibilidad es que las arras consistan en una cosa de la misma naturaleza de la vendida y las de el vendedor.

Al no ejercerse el derecho de retracto, las arras tendrían que devolverse. Operará la misma figura de la compensación, es decir: las arras se imputarán a la prestación debida, puesto que no tendría sentido que el comprador las deba devolver, para que el vendedor a su vez tenga que volverlas a traditar y entregar en ejecución del contrato de venta.

La cuarta alternativa es que las arras consistan en una cosa de la misma naturaleza de la vendida y las de el comprador. 
Aunque la figura no tendría mucho sentido práctico, de darse, obligará al vendedor a devolverlas, pues no habría causal para retenerlas.

Finalmente, piénsese en que las arras que dé el comprador o el vendedor no consistan en dinero o sean de naturaleza distinta a la vendida. En este evento, al no poder producirse ninguno de los efectos antes mencionados, tendrán en todo caso que devolverse.

\section{ARRAS SIMPLES Y CLÁUSULA PENAL}

No son pocos los casos en que en un contrato las partes pactan al tiempo arras simples, sea como garantía de celebración o de ejecución de un contrato y cláusula penal. Lo primero que cabe anotar, es que se trata de dos pactos antagónicos desde el punto de vista conceptual, pues tienen un alcance diferente. Como hemos insistido, las arras simples tiene la función de permitir el derecho lícito de retracto, sin que se genere incumplimiento del contrato y tampoco ninguna de sus consecuencias, entre ellas la indemnización por incumplimiento ${ }^{35}$. En

\footnotetext{
${ }^{35}$ Gómez EstradA, ob. cit., pág. 27. HinestrosA, FernAndo, "Contratos preparatorios. El contrato de promesa", en Revista de Derecho Privado, 11, Universidad Externado de Colombia, (2006), pág. 55. La Corte Suprema de Justicia ha señalado que la diferencia entre las arras "penitenciales" y la cláusula penal radica en que en la primera categoría, se faculta a cualquiera de los contratantes para retractarse de lo convenido, lo que no sucede con la segunda. "La finalidad de la cláusula penal es afirmar la ejecución de las obligaciones principalmente acordadas y por tanto ella no autoriza al deudor para exonerarse del cumplimiento de esas obligaciones. Obvio es que las partes, en ejercicio de su autonomía contractual, pueden pactar la que se denomina una multa penitencial o de
} 
cuanto a la cláusula penal, como se deduce del artículo 1592 del Código Civil, se trata de una estimación anticipada de perjuicios derivados del incumplimiento del contrato.

Así entonces, no se puede pensar en que una de las partes ejerce el derecho lícito de retracto y al tiempo incumple, pues precisamente si se retracta es porque ejercita un derecho que no puede ser calificado como incumplimiento. Por ello, es que en caso de presentarse debe prevalecer el derecho lícito de retirarse del contrato con el efecto propio de ello como anotaremos en el punto siguiente. Cabe que de todas formas pensar en que a pesar de pactarse al tiempo en un contrato el pacto de arras no aniquila del todo a la cláusula penal por incumplimiento, sino que la deja en suspenso. Se trata precisamente del evento en que el derecho de retracto caduca, bajo los supuestos ya enunciados. Así entonces, habiendo caducado el derecho de retracto que permite las arras, ya no podrá ninguna de las partes retirarse y en caso de negativa a cumplir, se activarían las reglas propias del incumplimiento, entre las cuales está la cláusula penal.

\section{ARRAS CONFIRMATORIAS}

arrepentimiento, o sea la estipulación de una multa para el caso de que alguno de los contratantes se retracte de la convención". Corte Suprema de Justicia, Sala de Casación Civil, 6 de marzo de 1961, M.P. Enrique López de la Pava, G.J., t. XCV, nº 2238, pág. 76. 
Las arras confirmatorias son las que aparecen reguladas en el artículo 1861 del Código Civil, así:

"Si expresamente se dieren arras como parte del precio, o como señal de quedar convenidos los contratantes, quedará perfecta la venta, sin perjuicio de lo prevenido en el artículo 1857 inciso 2".

La norma no establece cual de las dos partes debe entregar las arras, si el comprador o el vendedor, aunque de la redacción de la norma pareciere en principio que es el tidades que concomprador, cuando se den como parte del precio. Ahora, nada obsta para que las de el vendedor en señal de quedar convenidos.

\section{NATURALEZA JURÍDICA Y CONTENIDO}

Tal como se deriva de la norma transcrita, las arras confirmatorias tienen un carácter accesorio en el sentido de confirmar que las partes convienen celebrar un contrato, ya sea al pactar que se entregan como parte del precio o señal del convenio celebrado. Esto significa que las arras confirmatorias a diferencia de las simples, no generan derecho de retracto ${ }^{36}$. De acuerdo con esto, la única finalidad

\footnotetext{
${ }^{36}$ En la doctrina civilista argentina, BORDA afirma que los contratantes pueden decidir en virtud de la autonomía de la voluntad quitarle el efecto de retracto o arrepentimiento a las arras y decidir que más bien tendrán efecto confirmatorio. BORDA, GuILLERMO A., Tratado de Derecho Civil, Contratos, tomo I, con la colaboración de Alejandro Borda, $8^{\text {a }}$ edición, Lexis Nexis, Abeledo Perrot, Buenos Aires, 2005, pág. 241. Igualmente ALTERINI, ob. cit.,
} 
que tienen las arras confirmatorias, es la de adelantar efectos del contrato celebrado o de probar que las partes lo han celebrado ${ }^{37}$. Por ello, puede afirmarse

pág. 292. Cabe tener en cuenta que en el Derecho Comercial argentino, por el contrario del civil, las arras cumplen una función confirmatoria, salvo que las partes decidan darle el efecto de arrepentimiento, lo que deberá pactarse de forma especial en el contrato. Así lo establece el artículo 475 del Código de Comercio argentino: "Las cantidades que con el nombre de señal o arras se suelen entregar en las ventas, se entiende siempre que lo han sido por cuenta del precio y en signo de ratificación del contrato, sin que pueda ninguna de las partes retractarse, perdiendo las arras. Cuando el vendedor y el comprador convengan en que, mediante la pérdida de las arras o cantidad anticipada, les sea lícito arrepentirse y dejar de cumplir lo contratado, deberán expresarlo así por cláusula especial del contrato". Sobre el particular: MuÑOZ, LuIS, Derecho Comercial, Contratos, 1, Tipográfica Editora Argentina, Buenos Aires, 1960, págs. 232 y 233. A propósito de estas normas argentinas señala LORENZETTI: “....el pacto de una seña, sin expresión alguna sobre su finalidad, puede ser interpretado contextualmente y ser confirmatorio si el contrato es comercial (arts. $8^{\circ}$ y 475, Cód. Com.) y penitencial si es civil”. LOREnZETTI, RiCARDo LuIS, Tratado de los contratos, tomo 1, $2^{\text {a }}$ edición, Rubinzal Culzoni editores, Santa Fe, 2004, pág. 324. Sobre la necesidad de unificar el sistema civil y comercial de las arras en Argentina, véase Alterini, ob. cit., pág. 407. De forma similar en España, Cfr. Artículo 1454 del Código Civil español que consagra las arras de retracto. Por su lado, el artículo 343 del Código de Comercio español, consagra las arras en función confirmatoria, permitiendo que las partes pacten el derecho de retracto. "Artículo 343 Las cantidades que por vía de señal se entreguen en las ventas mercantiles se reputarán siempre dadas a cuenta del precio y en prueba de la ratificación del contrato, salvo pacto en contrario. En el Código Civil alemán, sólo se reconocen las arras confirmatorias, como lo establece el $\S 336$ (1). Véase al respecto: ENNECCERUS, LUDWIG, Derecho de obligaciones, volumen primero, doctrina general, undécima revisión por Enrich Lehmann, traducción por Blas Pérez González y José Alguer, $2^{a}$ edición al cuidado de José Puig Brutau, en Ludwig Enneccerus; THEodor Kipp; Martin Wolff, Tratado de Derecho Civil, segundo tomo, Derecho de obligaciones, 1, Bosch, Barcelona, 1954, págs. 184 a 187.

37 Como bien ha señalado la Corte Suprema de Justicia, "Si habiéndose estipulado arras simplemente confirmatorias el contrato se realiza, procede entonces su restitución por quien las recibió a quien las dio, o imputarse a buena cuenta del precio...". Corte Suprema de Justicia, Sala de Casación Civil, 10 de mayo de 1977, cit. En el Código Civil italiano, la "Seña confirmatoria" está consagrada en el artículo 1385: "Si en el momento de la conclusión del contrato, una de las partes diera a la otra, a título de seña, una suma de dinero o una cantidad de otras cosas fungibles, la seña, en caso de cumplimiento, deberá ser restituida o imputada a la prestación debida". No obstante, en el inciso segundo, se le da a la figura el carácter penitencial, en caso de incumplimiento de alguna de las prestaciones a cargo de las partes. En el Código Civil peruano, en el artículo 1477: "La entrega de arras 
que no tienen mucho sentido práctico, pues lo único que significan es, como lo indica Gómez EstradA, un símbolo o señal de que el contrato ha quedado concluido ${ }^{38}$.

También debemos indicar, como la misma norma lo aclara en la parte final del inciso primero, que se entiende perfeccionado el contrato sin perjuicio de lo dispuesto en el artículo 1857 inciso 2, esto es: si las partes hubiesen dado algo como parte del precio, o como señal de quedar convenidos, significa que se entiende perfeccionado el contrato, salvo en los casos en que el contrato a celebrar sea solemne, pues allí, no bastará el simple acuerdo, sino que el contrato no se entenderá perfeccionado, hasta tanto las partes no hayan formalizado el acuerdo.

Finalmente, debemos señalar que el pacto de arras confirmatorias está sometido a una solemnidad que consiste en una cláusula escrita que lo contenga, puesto que el inciso 2 del artículo 1861 expresa que si no consta por escrito que

confirmatorias importa la conclusión del contrato. En caso de cumplimiento, quien recibió las arras las devolverá o las imputará sobre su crédito, según la naturaleza de la prestación".

38 Por ello, tal como anota el autor: "En este caso, pues, el contrato es definitivo y ninguna de las partes puede retractarse de él sin cumplir lo pactado y hacerse acreedor a las sanciones consiguientes, la indemnización de perjuicios entre ellas. Aquí las arras no desempeñan papel de importancia ninguno, apenas son un símbolo de que el contrato ha quedado concluido. Si quien da las arras es el comprador, y solo podrá ser aquél cuando se den "como parte del precio", ellas constituyen un abono hecho a cuenta del precio de la venta”. GómEz EsTRADA, ob. cit., pág. 28. 
se trata de arras confirmatorias, se presume que las partes se pueden retractar, esto es: que las arras son simples ${ }^{39}$. Además de ello, se requiere la entrega de lo que se promete a título de arras toda vez que la norma misma señala que consisten en algo que se entrega al celebrar el contrato.

\section{Contratos en los que PUEDEN PACTARSE}

En el Derecho colombiano no existe norma alguna que impida que las partes pacten arras confirmatorias en cualquier tipo de contrato. Ello, a pesar de estar contenidas en el Código Civil, en las normas sobre compraventa. Ahora, de todas formas cabe considerar que el artículo 1861 del Código Civil pareciere restringirlas en los contratos preparatorios de promesa, al señalar que al pactar arras confirmatorias queda perfecta la venta. No obstante, pensamos que las partes, en virtud de la autonomía de la voluntad podrían decidir pactar arras confirmatorias incluso en un contrato de promesa, caso en el cual lo que dicho pacto produciría, es que las partes no pudieren retractarse del mismo.

\footnotetext{
39 "Lo cual significa que si al ajustar el contrato las partes no hacen constar expresamente en él que las arras se dan como parte del precio, o como señal de quedar convenidas, tiene que entenderse que fue su intención concederse la facultad de desistimiento de ese contrato; o, expresando la idea en forma tautológica, que en presencia de un pacto que se limita a estipular las arras, como dándolas el comprador al vendedor, sin hacer otra advertencia, la cuestión debe resolverse en el sentido de que hay lugar a la facultad de retractación". Corte Suprema de Justicia, Sala de Casación Civil, 10 de mayo de 1977, cit.
} 


\section{EFECTOS}

Señalamos ya que el principal efecto de las arras confirmatorias es probatorio, impidiendo además el retracto lícito del contrato. Ya sea que se den como parte del precio o como señal de quedar comprometidos los contratantes, las prestaciones derivadas del contrato deberán cumplirse de parte y parte so pena de que el acreedor de la prestación inejecutada acuda a las acciones generales sobre incumplimiento. Si el contrato se cumple y se dieron como parte del precio, a éste se imputarán y si se dio otra cosa, debe distinguirse si se trata de un bien de la misma naturaleza de la prestación debida, en cuyo caso a esta se imputarán, o de lo contrario, deberán devolverse pues nada faculta a quien las recibió a quedarse con ellas ${ }^{40}$.

Debe tenerse en cuenta que este tipo de arras no hacen las veces de estimación de perjuicios, en caso de un posible incumplimiento de parte de quien las haya entregado. Así lo ha señalado la Corte Suprema de Justicia:

“...si el contrato no se ejecuta, entonces si la parte que cumplió o se allanó a cumplir con las obligaciones que para ella generó la

\footnotetext{
${ }^{40}$ Esto último es lo que consagran otros ordenamientos, como el Código Civil italiano en el artículo 1385 primer inciso: "Si en el momento de la conclusión del contrato una de las partes diera a la otra, a título de seña una suma de dinero o una cantidad de otras cosas fungibles, la seña, en caso de cumplimiento, deberá ser restituida o imputada a la prestación debida" y el peruano en el 1477: "La entrega de arras confirmatorias importa la conclusión del contrato. En caso de cumplimiento, quien recibió las arras las devolverá o las imputará sobre su crédito, según la naturaleza de la prestación”.
} 
convención, puede acudir al Órgano Jurisdiccional del Poder Público en demanda del cumplimiento o la resolución del contrato, en ambos casos con indemnización de perjuicios" ${ }^{31}$.

Esto, a diferencia de otros ordenamientos como es el caso del Código Civil peruano, el cual en el artículo 1478 establece que: "Si la parte que hubiese entregado las arras no cumple la obligación por causa imputable a ella, la otra parte puede dejar sin efecto el contrato conservando las arras. Si quien no cumplió es la parte que las ha recibido, la otra puede dejar sin efecto el contrato y exigir el doble de las arras", norma que es igual al inciso 2 del artículo 1385 del Código Civil italiano: "Si la parte que hubiese dado la seña no cumpliese, la otra podrá rescindir el contrato reteniendo la seña; si por el contrario la incumplidora fuese la que la ha recibido, la otra podrá rescindir el contrato y exigir el doble de la seña".

De todas formas, este código permite al acreedor de la prestación incumplida, escoger entre esta función penal de las arras o acudir a las acciones generales por incumplimiento, como son la ejecución o la resolución del contrato junto con la indemnización de perjuicios regulada por las normas generales, tal como lo establece el artículo 1479, caso en el cual las arras deberán devolverse ${ }^{42}$.

\footnotetext{
${ }^{41}$ Corte Suprema de Justicia, Sala de Casación Civil, 10 de mayo de 1977, cit. En igual sentido: Corte Suprema de Justicia, Sala de Casación Civil, 11 de diciembre de 1978, cit.

${ }^{42}$ De la Puente y Lavalle, ob. cit. págs. 195 y 196.
} 
Por esto, consideramos que en dichos ordenamientos, se confunde la función y efecto de las arras de retracto y las confirmatorias en caso de incumplimiento, puesto que como puede verse tanto en el artículo 1386 del Código Civil italiano como en el 1481 del Código Civil peruano, el efecto del ejercicio del derecho de retracto, como sucede en Colombia con las arras simples, es la pérdida de las mismas o su devolución dobladas ${ }^{43}$. Tal vez la única diferencia radica en que las arras de retractación no comportan incumplimiento y ante el retiro de uno de los contratantes, el otro no podrá buscar la ejecución forzosa o la resolución del contrato, lo que a tenor del artículo 1479 del Código Civil peruano, como vimos anteriormente, si es una alternativa que se mantiene para el acreedor de la obligación inejecutada ${ }^{44}$.

\section{ARRAS CONFIRMATORIAS PENALES}

Esta categoría fue introducida en el Derecho colombiano por sentencia de la Corte Suprema de Justicia de 6 de junio de 1955, en la que se dijo que consisten en que uno de los contratantes da al otro arras como liquidación

\footnotetext{
${ }^{43}$ Art. 1386 inc. 2 C.C. it.: "En este caso, el que rescindiere perderá la seña dada o deberá restituir el doble de la recibida". Art. 1481 C.C. per.: "Si se retracta la parte que entrega las arras, las pierde en provecho del otro contratante. Si se retracta quien recibe las arras, debe devolverlas dobladas al tiempo de ejercitar el derecho".

44 Arias - Schreiber PeZET, MAX, Exegesis del Código Civil peruano de 1984, tomo 1, contratos: parte general, con la colaboración de Carlos Cardenas Quiroz; Angela Arias Schreiber M.; Elvira Martínez Coco, Gaceta Jurídica, 2a edición, Lima, 2000, págs. 342 a 346.
} 
anticipada de perjuicios, en cuyo caso la estipulación tiene los efectos de una cláusula penal, diferenciándose solo de aquella en que en las arras se está entregando anticipadamente la liquidación estimada de perjuicios, debidos en caso de incumplimiento ${ }^{45}$. Estableció la Corte en la referida sentencia que: "Arras confirmatorias penales dadas por uno de los contratantes al otro como liquidación anticipada de los perjuicios (ARRHA CONFIRMATORIA), en cuyo caso la estipulación tiene los caracteres de cláusula penal, de la que sólo se diferencia de aquella en cuanto ésta no es como aquéllas prestación real y antelada" ${ }^{46}$.

Cabe señalar que no obstante reconocerse a las arras simples una función "penitencial" y que según lo consideran algunos autores, esto las "aproxima" a una

45 Corte Suprema de Justicia, Sala de Casación Civil, 6 de junio de 1955, M.P. Manuel Barrera Parra, G.J., t. LXXX, n 1254, pág. 407. De esta misma forma: Corte Suprema de Justicia, Sala de Casación Civil, 1 de diciembre de 2004, M.P. Silvio Trejos, Exp. 54122. Véanse comentarios de la doctrina en: Gómez EstradA, ob. cit., pág. 28. BONIVENTO FERNÁNDEZ, José AlEJANDRO, De los principales contratos civiles y su paralelo con los comerciales, 16 $6^{\text {a }}$ edición, Ediciones Librería del Profesional, Bogotá, 2004, pág. 47 y 48. Igualmente Suescún Melo, ob. cit., pág. 42. Como se indicó anteriormente, el Código Civil italiano reconoce el valor de las arras confirmatorias penales en caso de incumplimiento. Igualmente se encuentran consagradas en la misma función en el Código Civil peruano, en el artículo 1478: "Si la parte que hubiere entregado las arras no cumple la obligación por causa imputable a ella, la otra parte puede dejar sin efecto el contrato conservando las arras. Si quien no cumplió es la parte que las ha recibido, la otra puede dejar sin efecto el contrato y exigir el doble de las arras". Nótese que el Código Civil peruano hace producir a las arras penales por incumplimiento contractual, el efecto que en otras codificaciones, como la colombiana, tiene las arras simples cuando se ejerce el derecho de retracto.

${ }^{46}$ Corte Suprema de Justicia, Sala de Casación Civil, 6 de junio de 1955, cit. 
cláusula penal ${ }^{47}$, la diferencia entre éstas y las confirmatorias penales radica en que mientras en las primeras el retracto es lícito y por ende ninguno de los dos podrá después de ejercidas, perseverar en el contrato, las segundas si constituyen una estipulación anticipada de perjuicios por el incumplimiento contractual, situación que permite a la parte agraviada con tal incumplimiento ejercer los derechos principales de ejecución forzosa o resolución.

De esta forma, resulta pertinente señalar con DíEZ PICAZO, que son éstas en realidad y no las arras simples o "penitenciales" las que cumplen una función de garantía. Se pronuncia así el catedrático español: "Las arras penales son las únicas que desarrollan una función estricta de garantía y presentan una indudable analogía con las cláusulas penales. La diferencia entre unas y otras estriba en que las primeras suponen promesa de entrega inicial que se destina a la otra parte para el caso de cumplimiento, con la promesa de entrega del duplo para la otra parte. Por lo demás, en orden a la función de liquidación del daño causado por el incumplimiento de estas arras deberá estarse a las mismas reglas establecidas para la multa convencional” ${ }^{48}$.

A nuestro modo de ver, existe un caso en el Derecho colombiano en el que no se admite el pacto de arras confirmatorias penales en el sentido indicado, que

\footnotetext{
47 Carvajal, ob. cit., pág. 531.

48 Diez PiCAZO, ob. cit., pág. 472.
} 
es el contrato de arrendamiento de vivienda urbana regulado por la Ley 820 de 2003. En efecto, esta norma consagra en el artículo 16 la prohibición de depósitos y cauciones reales para garantizar el cumplimiento de las obligaciones del arrendatario $^{49}$. Si se entiende a las arras confirmatorias penales como la entrega de una suma de dinero para garantizar el posible incumplimiento de una de las partes, efectivamente el concepto cabe dentro de las cauciones que la ley prohíbe pactar en este tipo de contratos. Más aun, si se atiende al segundo inciso del precepto, que insiste en que no importa cuál es la denominación que las partes le den, dentro de lo que cabrían la prenda, la cláusula penal, las arras confirmatorias penales, etc.

\section{CONCLUSIONES}

Además de los comentarios hechos a lo largo del texto, las principales conclusiones que se pueden derivar y explicitar de este trabajo, son:

\footnotetext{
${ }^{49}$ El texto de la norma dispone: "En los contratos de arrendamiento para vivienda urbana no se podrán exigir depósitos en dinero efectivo u otra clase de cauciones reales, para garantizar el cumplimiento de las obligaciones que conforme a dichos contratos haya asumido el arrendatario.

Tales garantías tampoco podrán estipularse indirectamente ni por interpuesta persona o pactarse en documentos distintos de aquél en que se haya consignado el contrato de arrendamiento, o sustituirse por otras bajo denominaciones diferentes de las indicadas en el inciso anterior".
} 
1. En el Derecho colombiano, civil y comercial, no se puede plantear un concepto genérico de arras, toda vez que cada una de sus especies: simples, confirmatorias o confirmatorias penales están llamadas a cumplir una función diferente y tiene unos efectos propios, por lo que puede resultar equívoco pensar en un concepto que las agrupe a todas.

2. A diferencia de algunos códigos extranjeros que no son claros sobre el particular, la regulación contenida en el Código Civil colombiano sobre arras, recoge las categorías romanas tanto del derecho clásico (arras confirmatorias) como postclásico (arras simples) además de una de creación jurisprudencial que son las arras confirmatorias penales.

3. En el Derecho colombiano no sólo se pueden dar arras simples representadas en dinero, sino en otro tipo de bienes y además, no sólo caben en contratos de promesa o de venta, así sea lo más usual en el tráfico. Igualmente, las puede dar cualquiera de las partes.

4. A pesar de lo que sugieren las normas que regulan las arras simples, éstas no cumplen una verdadera función de garantía, la cual incluso tampoco puede predicarse de las arras confirmatorias, pacto que además resulta inútil y constituyen tan sólo una reminiscencia del Derecho antiguo. El efecto propio de las arras simples es permitir el derecho de retracto, por lo que resulta evidente que no cumplen función de garantía dado que tal retracto no puede calificarse como incumplimiento. 
5. Resulta un tanto inútil pactar en un contrato arras simples como garantía de celebración o ejecución de un contrato y cláusula penal. Las dos figuras son antagónicas conceptualmente, puesto que mientras las primeras permiten el derecho lícito de retracto, las segundas constituyen una estimación anticipada de los perjuicios derivados del incumplimiento de un contrato. Esto conlleva que los efectos de cada una de las figuras no puedan ejercerse al tiempo. La única posibilidad al encontrarlas en un contrato, es esperar que el derecho de retracto caduque o sea renunciado de forma expresa o tácita para que pueda ejercerse la cláusula penal en caso de incumplimiento.

6. Son tan solo las arras confirmatorias penales, figura de creación jurisprudencial, de las que puede predicarse tal función, puesto que resultan ser a la manera de una cláusula penal, la forma de estimar anticipadamente los perjuicios derivados del incumplimiento. De lo anterior se deriva incluso que si las partes en efecto pretenden garantizar el cumplimiento de las obligaciones de un contrato, deben acudir a las propias formas de garantía. 
BIBLIOGRAFÍA

Alessandri Rodríguez, Arturo, De la Compraventa i de la promesa de venta, t. 1, Imprenta litográfica Barcelona, Santiago, 1918.

Alterini, Atilio Anibal, Contratos. Civiles - Comerciales - De consumo. Teoría General, Abeledo Perrot, Buenos Aires, 1998.

Alterini, Atilio Anibal; Ameal Oscar José; lópez Cabana, Roberto M., Derecho de obligaciones civiles y comerciales, $3^{\text {a }}$ edición, Lexis Nexis Abeledo Perrot, Buenos Aires, 2006.

AriAs - Schreiber Pezet, MaX, Exegesis del Código Civil peruano de 1984, tomo 1, contratos: parte general, con la colaboración de Carlos Cardenas Quiroz; Angela Arias - Schreiber M.; Elvira Martínez Coco, Gaceta Jurídica, 2ª edición, Lima, 2000.

Arrubla Paucar, Jaime Alberto, Contratos mercantiles, tomo 1, teoría general del negocio mercantil, 12ª edición, Dike, Medellín, 2007.

BADENES GASSET, RAMON, El contrato de compraventa, t. 1, 3ª edición, José María Bosch Editor S.A., Barcelona, 1995. 
Baena Upegui, Mario, De las obligaciones en Derecho Civil y Comercial, $3^{\underline{a}}$ edición, Legis, Bogotá, 2000.

Bonivento Fernández, José Alejandro, De los principales contratos civiles y su paralelo con los comerciales, 16 $6^{\underline{a}}$ edición, Ediciones Librería del Profesional, Bogotá D.C., 2004.

BONIVENTO JIMÉNEZ, JAVIER, El contrato de promesa. La promesa de compraventa de bienes inmuebles, Ediciones Librería del Profesional, Bogotá, 1996.

Borda, Guillermo A., Tratado de Derecho Civil, Contratos, tomo I, con la colaboración de Alejandro Borda, 8ª edición, Lexis Nexis, Abeledo Perrot, Buenos Aires, 2005.

Carvajal R, Patricio-Ignacio, "Las Arras en el Derecho Justinianeo", en Revista chilena de Derecho, vol.33, no.3, (2006), págs. 529 a 560.

Colin, Ambrosio; Capitant, Henri, Curso elemental de Derecho Civil, Demófilo de Buen (Trad.), t. 4, 3ª edición, Instituto editorial Reus, Madrid, 1955. 
Compagnucci de Caso, Rubén H., Contrato de compraventa, Hammurabi, Buenos Aires, 2007.

De la Puente y Lavalle, Manuel, El contrato en general, comentarios a la sección primera del libro VII del Código Civil, Biblioteca para Leer el Código Civil, vol. XV, segunda parte, tomo VI, Pontificia Universidad Católica del Perú, Lima, 1999.

Díez PICAzo, LuIS, Fundamentos del Derecho Civil patrimonial, II, las relaciones obligatorias, 6ª edición, Thomson Civitas, Cizur Menor, 2008.

Domat, J., Las leyes civiles en su orden natural, edición española de Felio Vilarrublas y José Sardá, 2ª edición, Barcelona, 1844.

D’Ors, Alvaro, Derecho Privado Romano, 10ª edición, Eunsa, Pamplona, 2004.

ENNECCERUS, LUDWIG, Derecho de obligaciones, volumen primero, doctrina general, undécima revisión por Enrich Lehmann, traducción por Blas Pérez González y José Alguer, $2^{\underline{a}}$ edición al cuidado de José Puig Brutau, en Ludwig Enneccerus; THEodor Kipp; Martin Wolff, Tratado de Derecho Civil, segundo tomo, Derecho de obligaciones, 1, Bosch, Barcelona, 1954. 
Guzmán Brito, Alejandro, Derecho Privado Romano, Tomo II, Editorial Jurídica de Chile, Santiago, 2001.

Gómez Estrada, CÉSAR, De los principales contratos civiles, 4aㅡ edición, Temis, Bogotá, 2008.

GonzÁlez Zabala, María Clara, "De las funciones de las arras en el derecho privado colombiano y en el derecho comparado" en Estudios de Derecho Privado, tomo 1, liber amicorum en homenaje a César Gómez Estrada, Universidad del Rosario, Bogotá, 2009, págs. 369 a 393.

HeRnANDez Gil, Felix, Las arras en el derecho de la contratación (en torno al artículo 1.454 del Código Civil), Universidad de Salamanca, Salamanca, 1958.

Hinestrosa, Fernando, "Contratos preparatorios. El contrato de promesa", en Revista de Derecho Privado, 11, Universidad Externado de Colombia, (2006), págs. 33 a 56.

LORENZETTI, RICARDo LUIS, Tratado de los contratos, tomo 1, 2ª edición, Rubinzal Culzoni editores, Santa Fe, 2004. 
Messineo, Francesco, Derecho Civil y Comercial, II, Doctrinas generales, Santiago Sentis Melendo (trad.), Ediciones Jurídicas Europa América, Buenos Aires, 1979.

Messineo, Francesco, Doctrina general del contrato, R.O. Fontanarrosa, S. Sentis Melendo, M. Volterra, (trads.), dos tomos, Ediciones Jurídicas Europa América, Buenos Aires, 1986.

Meza Barros, Ramón, Manual de Derecho Civil, De las fuentes de las obligaciones, tomo 1, 8ª edición, Editorial Jurídica de Chile, Santiago, 2000.

Mosset ItURRASPe, Jorge, Contratos, Rubinzal Culzoni editores, Santa Fe, 2003.

MuÑOz, LUIS, Derecho Comercial, Contratos, 1, Tipográfica Editora Argentina, Buenos Aires, 1960.

Narváez García, José Ignacio, Derecho mercantil colombiano. Obligaciones y contratos mercantiles, $2^{\mathrm{a}}$ edición, Legis, Bogotá, 2002.

Pérez Vives, Álvaro, Compraventa y permuta, 2ª edición, Temis, Bogotá, 1953. 
Pérez Vives, Álvaro, Teoría general de las obligaciones, volumen 1, parte primera, 2ª edición, Universidad Nacional de Colombia, Bogotá, 1957.

Planiol, Marcelo; RiPert, Jorge, Tratado práctico de Derecho Civil francés, tomo $X$, Los contratos civiles, traducción española de Mario Díaz Cruz con la colaboración de Eduardo Le Riverend Brusone, Cultural S.A., Habana, 1940.

POTHIER, JOSEPH, Tratado del contrato de compra y venta, traducido al español y con notas del derecho patrio por una sociedad de amigos colaboradores, Imprenta y Litografía de J. Roger, Barcelona, 1841.

Ripert, Georges; Boulanger, Jean, Tratado de Derecho Civil según el tratado de Planiol, Contratos Civiles, traducción de Delia García Daireaux, La Ley, Buenos Aires, 1965.

Rodríguez Fonnegra, JaIme, Del contrato de compraventa y materias aledañas, Ediciones Lerner, Bogotá, 1960.

Samper, Francisco, Derecho romano, $2^{\text {a }}$ edición, Pontificia Universidad Católica de Chile, Santiago, 2007. 
Suescún Melo, Jorge, Derecho Privado. Estudios de Derecho Civil y Comercial contemporáneo, t. I, ª edición, Universidad de los Andes, Legis, Bogotá, 2003.

Tamayo lombana, Alberto, El contrato de compraventa, su régimen civil y comercial, Ediciones Doctrina y Ley Ltda., Bogotá D.C., 2004.

Vélez, Fernnando, Estudio sobre el Derecho Civil Colombiano, tomo séptimo, Imprenta oficial, Medellín, 1909.

Zimmermann, Reinhard, The law of obligations. Roman foundations of the civilian tradition, Oxford, New York, 1996.

TEXTOS HISTÓRICO JURÍDICOS

INSTITUCIONES JURÍDICAS DE GAYO, Francisco Samper, (Traductor), Editorial Jurídica de Chile, Santiago, 2000.

VII Partidas del sabio Rey don alfonso el iX, con las variantes de más interes y con La Glosa del Lic. Gregorio López, Imprenta de Antonio Bergnes, Barcelona, 1843-1844. 
Cuerpo del Derecho Civil Romano, T.1., Instituta - Digesto, primera, segunda y tercera partes, Justiniano García del Corral, Ildefonso, (Traductor y compilador), Jaime Molinas Editor, Barcelona, 1889.

\section{FALLOS CITADOS}

Corte Suprema de Justicia, Sala de Casación Civil, 30 de julio de 1941, M.P. Hernán Salamanca, G.J., t. LII, n 1977, 1941, pág. 18.

Corte Suprema de Justicia, Sala de Casación Civil, 10 de julio de 1953, M.P. Pablo Emilio Manotas, G.J., t. LXXV, n²129, 1953, pág. 548.

Corte Suprema de Justicia, Sala de Casación Civil, 6 de octubre de 1953, M.P. Pablo Emilio Manotas, G.J., t. LXXVI, n²133, 1953, pág. 506.

Corte Suprema de Justicia, Sala de Casación Civil, 6 de junio de 1955, M.P. Manuel Barrera Parra, G.J., t. LXXX, n 1254, pág. 407.

Corte Suprema de Justicia, Sala de Casación Civil, 6 de marzo de 1961, M.P. Enrique López de la Pava, G.J., t. XCV, n 2238, pág. 76. 
Corte Suprema de Justicia, Sala de Casación Civil, 21 de febrero de 1967, M.P. Gustavo Fajardo Pinzón, G.J., t. CXIX, núms. 2285 y 2286, 1967, pág. 47.

Corte Suprema de Justicia, Sala de Casación Civil, 10 de mayo de 1977, M.P. Humberto Murcia Ballen, G.J., t. CLV, núm. 2396, 1977, pág. 106.

Corte Suprema de Justicia, Sala de Casación Civil, 11 de diciembre de 1978, M.P. Alberto Ospina Botero, G.J., t. CLVIII, n² 2399, 1978, pág. 311.

Corte Suprema de Justicia, Sala de Casación Civil y Agraria, 7 de septiembre de 1999, M.P., Manuel Ardila Velásquez, exp. 5217.

Corte Suprema de Justicia, Sala de Casación Civil, 1 de diciembre de 2004, M.P. Silvio Trejos, Exp. 54122. 